Research

Open Access

\title{
Impact of intraoperative lung-protective interventions in patients undergoing lung cancer surgery
}

\author{
Marc Licker ${ }^{1}$, John Diaper ${ }^{1}$, Yann Villiger ${ }^{1}$, Anastase Spiliopoulos², Virginie Licker ${ }^{3}$, John Robert ${ }^{4}$ \\ and Jean-Marie Tschopp 5
}

\author{
1Department of Anaesthesiology, Pharmacology and Intensive Care, Faculty of Medicine, University of Geneva, rue Micheli-du-Crest, $\mathrm{CH}-1211$ \\ Geneva, Switzerland \\ ${ }^{2}$ Clinique des Grangettes and Faculty of Medicine, University of Geneva, $\mathrm{CH}-1224$ Geneva, Switzerland \\ ${ }^{3}$ Biomedical Proteomics Group, Department of Structural Biology and Bioinformatics, Faculty of Medicine, University of Geneva, CH-1211 Geneva, \\ Switzerland \\ ${ }^{4}$ Department of Thoracic Surgery and Faculty of Medicine, University Hospital, $\mathrm{CH}-1211$ Geneva, Switzerland \\ ${ }^{5}$ Department of Internal Medicine, Chest Medical Centre, $\mathrm{CH}-3960$ Montana and Faculty of Medicine, University of Geneva, $\mathrm{CH}-1211 \mathrm{Geneva}$, \\ Switzerland
}

Corresponding author: Marc Licker, licker-marc-joseph@diogenes.hcuge.ch

Received: 27 Jan 2009 Revisions requested: 19 Feb 2009 Revisions received: 2 Mar 2009 Accepted: 24 Mar 2009 Published: 24 Mar 2009

Critical Care 2009, 13:R41 (doi:10.1186/cc7762)

This article is online at: http://ccforum.com/content/13/2/R41

(c) 2009 Licker et al.; licensee BioMed Central Ltd.

This is an open access article distributed under the terms of the Creative Commons Attribution License (http://creativecommons.org/licenses/by/2.0), which permits unrestricted use, distribution, and reproduction in any medium, provided the original work is properly cited.

\begin{abstract}
Introduction In lung cancer surgery, large tidal volume and elevated inspiratory pressure are known risk factors of acute lung (ALI). Mechanical ventilation with low tidal volume has been shown to attenuate lung injuries in critically ill patients. In the current study, we assessed the impact of a protective lung ventilation (PLV) protocol in patients undergoing lung cancer resection.
\end{abstract}

Methods We performed a secondary analysis of an observational cohort. Demographic, surgical, clinical and outcome data were prospectively collected over a 10-year period. The PLV protocol consisted of small tidal volume, limiting maximal pressure ventilation and adding end-expiratory positive pressure along with recruitment maneuvers. Multivariate analysis with logistic regression was performed and data were compared before and after implementation of the PLV protocol: from 1998 to 2003 (historical group, $n=533$ ) and from 2003 to 2008 (protocol group, $\mathrm{n}=558$ ).

Results Baseline patient characteristics were similar in the two cohorts, except for a higher cardiovascular risk profile in the intervention group. During one-lung ventilation, protocolmanaged patients had lower tidal volume $(5.3 \pm 1.1$ vs. $7.1 \pm$ $1.2 \mathrm{ml} / \mathrm{kg}$ in historical controls, $P=0.013$ ) and higher dynamic compliance ( $45 \pm 8$ vs. $32 \pm 7 \mathrm{ml} / \mathrm{cmH}_{2} \mathrm{O}, P=0.011$ ). After implementing PLV, there was a decreased incidence of acute lung injury (from $3.7 \%$ to $0.9 \%, P<0.01$ ) and atelectasis (from 8.8 to $5.0, P=0.018$ ), fewer admissions to the intensive care unit (from $9.4 \%$ vs. $2.5 \%, P<0.001$ ) and shorter hospital stay (from $14.5 \pm 3.3$ vs. $11.8 \pm 4.1, P<0.01$ ). When adjusted for baseline characteristics, implementation of the open-lung protocol was associated with a reduced risk of acute lung injury (adjusted odds ratio of 0.34 with 95\% confidence interval of 0.23 to $0.75 ; P=0.002$ ).

Conclusions Implementing an intraoperative PLV protocol in patients undergoing lung cancer resection was associated with improved postoperative respiratory outcomes as evidence by significantly reduced incidences of acute lung injury and atelectasis along with reduced utilization of intensive care unit resources.

\section{Introduction}

Compared with other surgical procedures, thoracotomy is associated with the highest 30-day mortality rates, ranging from less than $1 \%$ for minor resections to up to $12 \%$ for pneumonectomies [1-3]. Postoperative onset of acute hypoxemia - unrelated to cardiac failure, pulmonary embolism, atelectasis, sepsis or bronchoaspiration - has attracted much interest as it has become the leading cause of death in patients undergoing lung resection $[4,5]$. The guidelines set forth by the American-European Consensus Conference on the acute

ALI: acute lung injury; ICU: intensive care unit; $\mathrm{PaO}_{2} / \mathrm{FIO}_{2}$ ratio: oxygenation index, ratio of arterial oxygen pressure to inspired oxygen fraction; PBW: predicted body weight; PEEP: positive end-expiratory pressure; PLV: protective lung ventilation; TNF: tumor necrosis factor; $\mathrm{V}_{\mathrm{T}}$ : tidal volume. 
respiratory distress syndrome have been widely adopted to describe this form of acute lung injury (ALI), previously coined postpneumonectomy pulmonary edema, low-pressure or lowpermeability pulmonary edema [6].

Contrasting with other adverse cardiopulmonary events, the incidence of post-thoracotomy ALI has not shown any noticeable decrease although various treatment modalities such as noninvasive ventilation and nitric oxide inhalation have reduced the case-fatality rate $[7,8]$. Interestingly, a large tidal volume $\left(\mathrm{V}_{\mathrm{T}}\right)$ and an elevated inspiratory pressure during one-lung ventilation have been identified as strong predictors of ALI in two retrospective observational studies $[9,10]$. The hypothesis of ventilator-induced lung injury during one-lung ventilation has been further supported by the association between tidal volume exceeding 7 to $8 \mathrm{ml} / \mathrm{kg}$ predicted body weight (PBW) and the release of systemic and pulmonary inflammatory mediators [11]. Presently, the clinical benefits of lung-protective strategies using lower $V_{T}$ combined with positive end-expiratory pressure (PEEP) have been clearly demonstrated in randomized controlled trials including only critically ill patients with $\mathrm{ALI} /$ acute respiratory distress syndrome [12].

Considering the potential injurious effects of large tidal volume in patients with healthy lungs undergoing short-term one-lung ventilation, we hypothesized that adopting a protective lung ventilation (PLV) protocol as part of a collaborative quality improvement initiative would lead to further reduction in the incidence of post-thoracotomy ALI. In our institutional surgical database, we examined whether protocol-driven changes in ventilatory strategy initiated in 2003 were associated with better clinical outcomes compared with historical controls.

\section{Materials and methods Study design and settings}

The retrospective cohort study was approved by the Institutional Research Board and included all consecutive cases of lung cancer resection performed in two affiliated medical institutions: an academic center (Hôpitaux Universitaires de Genève) and a tertiary reference hospital (Centre Valaisan de Pneumologie in Sion). As the study concerned retrospective analysis of data obtained during usual clinical practice, local regulations do not require written informed consent. All patients were operated on by one of two board-certified thoracic surgeons and were managed by the same team of cardiothoracic anesthesiologists.

Since 1 March 2003 the PLV strategy has been routinely implemented as a best-practice model for intraoperative management (PLV cohort, from March 2003 to March 2008). This PLV group entailed the application of low $V_{T}(<8 \mathrm{ml} / \mathrm{kg} P B W)$, pressure-controlled ventilation, limitation of the inspiratory plateau pressure to $35 \mathrm{cmH}_{2} \mathrm{O}$, the addition of external PEEP (4 and $10 \mathrm{cmH}_{2} \mathrm{O}$ ) and performance of vital-capacity maneuvers (raising the inspiratory pressure up to $35 \mathrm{cmH}_{2} \mathrm{O}$ for 7 to 10 seconds) at 30-minute intervals.

In our database we abstracted a comparison group of nonprotocolized consecutive patients undergoing operation during the preceding 5 years (1998 to 2003), these patients being referred as the historical control cohort. In this group, conventional volume-targeted ventilation was aimed to achieve $V_{T}$ of 9 to $12 \mathrm{ml} / \mathrm{kg}$ PBW during two-lung ventilation and of 8 to 10 $\mathrm{ml} / \mathrm{kg}$ PBW during one-lung ventilation while avoiding inspiratory pressure exceeding $35 \mathrm{cmH}_{2} \mathrm{O}$; no recruitment maneuver was performed and PEEP was applied at the discretion of the attending anesthesiologist.

In both groups, the same anesthetic workstations were used (Dräger Primus or Zeus, Lübeck, Germany) with the respiratory rates and the oxygen inspiratory fraction adjusted to keep the end-tidal carbon dioxide between 4 and $6 \mathrm{kPa}$ (30 and 45 $\mathrm{mmHg}$ ) and to keep the arterial pulsed oxygen saturation above $90 \%$.

The main outcome of interest was the development of ALI, defined according to the American-European Consensus Conference criteria as follows: sudden onset of respiratory distress; infiltrates on the chest radiograph consistent with pulmonary edema; impaired oxygenation with an arterial oxygen pressure-to-inspired oxygen fraction ratio $\left(\mathrm{PaO}_{2} / \mathrm{FIO}_{2}\right.$ ratio) less than $300 \mathrm{mmHg}$ for $\mathrm{ALI}$; and absence of cardiac insufficiency or fluid overload, based on pulmonary arterial catheterization, echocardiogram and/or clinical evaluation [6]. Additional criteria for post-thoracotomy ALI included the onset respiratory distress within the first 48 hours after surgery. Patients presenting with aspiration of gastric contents, pneumonia, bronchopleural fistula or pulmonary embolism who later developed noncardiogenic pulmonary edema were considered secondary ALI patients if they fulfilled the AmericanEuropean Consensus Conference criteria.

Secondary outcome variables were inhospital mortality, intensive care unit (ICU) admissions, duration of hospital stay as well as respiratory, cardiovascular and surgical complications (see Additional data file 1).

In a previous study, we reported a $4.2 \%$ incidence of post-thoracotomy ALI [10]. A sample size of 1,000 operated patients provided the power ( $80 \%)$ to detect a $50 \%$ relative risk reduction in post-thoracotomy ALI. The sample size therefore resulted from an a priori decision to limit the analysis to two consecutive periods, before and after implementing the PLV strategy, including at least 500 patients per group.

\section{Patients and perioperative management}

Besides clinical evaluation, electrocardiography and laboratory screening, routine preoperative work-up included pulmonary function tests (Sensor Medics, Yorba Linda, CA, USA) 
with the lung diffusion capacity to carbon monoxide, lung biopsy, CT scan and/or positron emission tomography of the chest and abdomen. Patients with borderline spirometric results (forced expiratory volume in 1 second lower than $60 \%$ to $80 \%$ of the predicted value), impaired exercise tolerance or cardiac risk factors underwent complementary investigations (peak oxygen consumption, differential lung perfusion/ventilation scan, echocardiography, thallium myocardial scintigraphy and/or coronary angiogram).

After anesthesia induction, a left-sided double-lumen tube was inserted and its correct position was confirmed by fiberoptic bronchoscopy. Lung resection with systematic lymph node dissection was performed through an anterolateral musclesparing thoracotomy. Thoracic epidural anesthesia was initiated intraoperatively and continued postoperatively until chest-drain removal.

Intraoperatively, intravenous crystalloids were infused at a rate of 2 to $4 \mathrm{ml} / \mathrm{kg} / \mathrm{hour}$ and blood losses were compensated with colloids and with red blood cell concentrates if the hemoglobin levels decreased below 80 to $90 \mathrm{~g} / \mathrm{l}$. All patients were extubated in the operating theater and were admitted to an intermediate care unit for at least 12 hours before being transferred to the surgical ward. During the first 48 hours after surgery, aerosolized salbutamol and ipratropium were routinely prescribed and a fluid balance of maximum $500 \mathrm{ml} /$ day was targeted, by limiting oral and intravenous fluid intakes. A restrictive transfusion policy was adopted throughout both study periods, with transfusion triggers ranging between 80 and $95 \mathrm{~g} / \mathrm{l}$. Antimicrobial prophylaxis with cefazoline was administered for 24 hours.

\section{Data collection}

Demographic, clinical, surgical and anesthetic data as well as perioperative complications were abstracted from a prospective registry including all patients who underwent thoracic surgery. These data were collected by study nurses, entered into the surgical database in the same manner during both study periods and were cross-checked for accuracy. Before surgical incision and $\mathbf{3 0}$ minutes after the start of one-lung ventilation, the following ventilatory data were recorded: $\mathrm{V}_{\mathrm{T}}(\mathrm{ml} / \mathrm{kg}$ PBW), inspiratory plateau pressure, PEEP and $\mathrm{FIO}_{2}$. The effective dynamic compliance was obtained by dividing the ventilatordelivered $V_{T}$ by the peak airway pressure minus the PEEP. Intraoperatively and postoperatively, the use of vasopressor drugs was recorded as well as the urine output and the amount of fluid intake (colloids, crystalloids and blood products). On the first day after surgery, arterial oxygen pressure $\left(\mathrm{PaO}_{2}\right.$ in $\mathrm{kPa}$ ) was measured using a blood gas analyzer (ABL510 analyzer; Radiometer, Copenhagen, Denmark) and the $\mathrm{PaO}_{2} / \mathrm{FIO}_{2}$ ratio was calculated as the $\mathrm{PaO}_{2} / \mathrm{FIO}_{2}$ ratio. Postoperative complications were defined according to standard criteria (see Additional data file 1).

\section{Statistical analysis}

For comparisons between the two cohorts, the unpaired Student $t$ test was used for normally distributed data and the Mann-Whitney $U$ test for non-normally distributed data. The Kolmogorov-Smirnov test was applied to decide whether the cohorts were normally distributed. The prevalence of risk factors and the incidence of complications in the two groups were compared by Fisher exact test. Multivariate logistic regression analysis using backward selection was performed to assess whether demographic, clinical, laboratory and surgical factors, fluid and ventilatory management were associated with the occurrence of primary ALI. We choose an inclusive cutoff value for the empiric level of significance $(P<0.2)$ at which we retained variables. The final model was assessed for goodness of fit using the Hosmer-Lesmeshow test and for omitted covariates and model misspecification using the link test [13]. All analyses were performed using SPSS software (version 14.0 for Microsoft Windows; SPSS, Chicago, IL, USA) and statistical significance was specified as a two-tailed type I error ( $P$ value) set below the 0.05 level.

\section{Results}

Over a 10-year period, 1,091 patients underwent pulmonary resection for malignancy. Complete data were available in 533 patients from 1 March 1997 to 28 February 2003 and in 558 patients from 1 March 2003 to 28 February 2008.

As detailed in Table 1, baseline characteristics of patients were similar between the two cohorts - except for a higher cardiovascular risk profile in the PLV cohort, as evidenced by a greater prevalence of hypertension and diabetes mellitus along with more frequent prescription of cardiovascular drugs.

The type of surgery, the distribution of pathological cancer stages, the need for chemoradiotherapy as well as the duration of one-lung ventilation and surgery did not differ between the groups (Table 2). Fluid and vasopressor therapies were also similar; however, a higher proportion of patients received continuous thoracic epidural anesthesia in the PLV cohort compared with the historical controls $(98.2 \%$ vs. $92.3 \%, P<$ 0.05).

During one-lung ventilation $\mathrm{V}_{T}<8 \mathrm{ml} / \mathrm{kg}$ was achieved in $92 \%$ of protocolized PLV patients (vs. $24 \%$ in historical controls), resulting in significantly lower $\mathrm{V}_{\mathrm{T}}$ and inspiratory plateau pressure, while the dynamic compliance, PEEP and respiratory rate were significantly higher compared with the historical control cohort (Table 3).

In the PLV cohort there was a reduction in the frequency of post-thoracotomy ALI (from 3.7\% to $0.9 \%$ in the historical control cohort; $P<0.01$ ) along with a lower incidence of atelectasis, fewer admissions to the ICU and a shorter hospital stay (Table 4). In the control cohort, patients ventilated with $V_{T}$ 
Critical Care Vol 13 No 2 Licker et al.

Table 1

Preoperative characteristics of the two cohorts of thoracic surgical patients

\begin{tabular}{|c|c|c|c|}
\hline & Historical control cohort $(n=533)$ & PLV cohort $(n=558)$ & $P$ value \\
\hline Age & $62(12)$ & $63(12)$ & 0.956 \\
\hline$>70$ years $(\%)$ & 29 & 30 & 0.568 \\
\hline Gender, female (\%) & 35.6 & $36.9^{\star}$ & 0.709 \\
\hline Body mass index $\left(\mathrm{kg} / \mathrm{m}^{2}\right)$ & $25.1(4.6)$ & $25.3(5.1)$ & 0.567 \\
\hline \multicolumn{4}{|l|}{ Smoking (\%) } \\
\hline Current & 66.2 & 63.8 & 0.724 \\
\hline Ex-smoker (>6 months) & 10.1 & 11.3 & 0.884 \\
\hline Alcohol (>60 g/day) & 13.1 & 14.2 & 0.686 \\
\hline ASA classes 3 and $4(\%)$ & 42.2 & $48.4^{*}$ & 0.047 \\
\hline \multicolumn{4}{|l|}{ Comorbidities (\%) } \\
\hline Hypertension & 24.4 & $35.1^{*}$ & $<0.01$ \\
\hline Coronary artery disease & 8.4 & $9.7^{*}$ & 0.546 \\
\hline Heart failure & 5.8 & $8.7^{\star}$ & 0.066 \\
\hline Hypercholesterolemia & 16.7 & $22.9^{\star}$ & 0.013 \\
\hline Peripheral artery disease & 7.5 & 7.6 & 0.951 \\
\hline Diabetes mellitus & 9.6 & 10.7 & 0.045 \\
\hline Arrythmia & 2.1 & 2.7 & 0.633 \\
\hline Conduction blockade & 8.4 & 7.3 & 0.576 \\
\hline Stroke & 2.4 & 2.8 & 0.602 \\
\hline Prior PTCA/CABGS (\%) & 2.6 & 4.3 & 0.179 \\
\hline \multicolumn{4}{|l|}{ Preoperative medications (\%) } \\
\hline$\beta$-Blockers & 5.6 & $10.4^{*}$ & 0.006 \\
\hline ACE inhibitors/angiotensin II antagonists & 11.1 & $16.5^{\star}$ & 0.012 \\
\hline Statins & 8.1 & 9.7 & 0.534 \\
\hline Corticoids & 3.9 & 4.1 & 0.999 \\
\hline Antiplatelets & 4.1 & $7.4^{\star}$ & 0.032 \\
\hline Calcium channel blockers & 3.7 & 4.1 & 0.874 \\
\hline \multicolumn{4}{|l|}{ Lung function } \\
\hline Forced vital capacity (I/min) & $3.51(1.07)$ & $3.49(0.96)$ & 0.885 \\
\hline Forced vital capacity (\% predicted value) & $95(21)$ & $92(22)$ & 0.798 \\
\hline FEV1 (I/min) & $2.5(1.1)$ & $2.4(0.9)$ & 0.825 \\
\hline FEV1 (\% predicted value) & $82(18)$ & $81(19)$ & 0.912 \\
\hline Total lung capacity (I/min) & $6.2(1.4)$ & $6.3(1.8)$ & 0.892 \\
\hline Total lung capacity (\% predicted value) & $102(18)$ & $101(17)$ & 0.921 \\
\hline Carbon monoxide diffusion capacity (\% predicted value) & $54(14)$ & $53(13)$ & 0.896 \\
\hline \multicolumn{4}{|l|}{ Laboratory data } \\
\hline Hematocrit (\%) & $41.0(5.1)$ & $40.8(4.9)$ & 0.885 \\
\hline Creatinine clearance $(\mathrm{ml} / \mathrm{min})$ & $83(23)$ & $85(28)$ & 0.387 \\
\hline
\end{tabular}

Data presented as mean (standard deviation) or percentage. ACE, angiotensin-converting enzyme; ASA, American Society of Anesthesiologists; CABGS, coronary artery bypass graft surgery; FEV1, forced expiratory volume in the first second; PLV, protective lung ventilation; PTCA, percutaneous coronary angioplasty. ${ }^{\star} P<0.05$ between the two groups. 
Table 2

Perioperative surgical and medical characteristics

\begin{tabular}{|c|c|c|c|}
\hline & Historical control cohort $(n=533)$ & PLV cohort $(n=558)$ & $P$ value \\
\hline Preoperative chemotherapy & 10.8 & 14.4 & 0.080 \\
\hline \multicolumn{4}{|l|}{ Type of surgery (\% cases) } \\
\hline Pneumonectomy or bi-lobectomy & 21.4 & 17.6 & 0.129 \\
\hline Lobectomy & 54.2 & 56.1 & 0.575 \\
\hline Lesser resection & 18.7 & 20.5 & 0.542 \\
\hline Explorative thoracotomy & 5.4 & 3.2 & 0.099 \\
\hline \multicolumn{4}{|l|}{ Pathologic stage (\% patients) } \\
\hline $\mathrm{la}$ and $\mathrm{lb}$ & 42 & 44 & 0.531 \\
\hline $\mathrm{Ila}$ and $\mathrm{Ilb}$ & 22 & 23 & 0.750 \\
\hline Illa & 18 & 19 & 0.733 \\
\hline IIllb and IV & 11 & 8 & 0.389 \\
\hline Other & 7 & 6 & 0.833 \\
\hline Thoracic epidural analgesia (\% patients) & 83.7 & $95.0^{*}$ & $<0.001$ \\
\hline \multicolumn{4}{|l|}{ Intraoperative period } \\
\hline Duration of anesthesia (minutes) & $166(62)$ & $176(74)$ & 0.228 \\
\hline Duration of surgery (minutes) & $114(47)$ & $121(56)$ & 0.354 \\
\hline Duration of one-lung ventilation (minutes) & $71(18)$ & $74(20)$ & 0.421 \\
\hline Total intraoperative fluid intake (ml/kg/hour) & $5.6(2.8)$ & $5.8(2.9)$ & 0.587 \\
\hline Intravenous crystalloids (ml/kg/hour) & $3.6(1.4)$ & $3.5(1.6)$ & 0.652 \\
\hline Intravenous colloids ( $\mathrm{ml} / \mathrm{kg} / \mathrm{hour}$ ) & $2.0(1.5)$ & $2.3(1.8)$ & 0.187 \\
\hline Red blood cell transfusion (\% patients) & 1.50 & 1.61 & 0.991 \\
\hline Urine output (ml/kg/hour) & $1.8(1.2)$ & $1.5(1.4)$ & 0.287 \\
\hline Phenylephrine (mg) & $528(443)$ & $588(487)$ & 0.338 \\
\hline Ephedrine (mg) & $15(13)$ & $16(14)$ & 0.542 \\
\hline Cumulative fluid intake (24 hours) ( $\mathrm{ml} / \mathrm{kg} / \mathrm{hour}$ ) & $6.4(3.2)$ & $6.6(3.1)$ & 0.385 \\
\hline \multicolumn{4}{|l|}{ Postoperative period } \\
\hline Total fluid intake ( $\mathrm{ml} / 24$ hours) & $1,657(573)$ & $1,496(608)$ & 0.182 \\
\hline Red blood cell transfusion (\% patients) & 2.25 & 1.79 & 0.890 \\
\hline Urine output ( $\mathrm{ml} / 24$ hours) & $868(334)$ & $781(234)$ & 0.254 \\
\hline Chest drainage ( $\mathrm{ml} / 24$ hours) & $378(172)$ & $342(125)$ & 0.774 \\
\hline $\mathrm{PaO}_{2} / \mathrm{FIO}_{2}(\mathrm{kPa})$ & $45.1(6.2)$ & $44.7(5.9)$ & 0.513 \\
\hline Blood hemoglobin at POD1 ( $\mathrm{g} / \mathrm{l})$ & $119(13)$ & $121(20)$ & 0.834 \\
\hline Serum creatinine at POD1 (mg/l) & $93(30)$ & $84(31)$ & 0.303 \\
\hline
\end{tabular}

Data presented as mean (standard deviation), $n$ (\%) or percentage. $\mathrm{PaO}_{2} / \mathrm{FIO}_{2}$, ratio of arterial oxygen pressure to inspiratory fraction of oxygen; PLV, protective lung ventilation; POD1, first postoperative day. ${ }^{\star} P<0.05$ between the two groups. 


\begin{tabular}{|c|c|c|}
\hline & Historical control cohort $(n=533)$ & PLV cohort $(n=558)$ \\
\hline \multicolumn{3}{|l|}{ Two-lung ventilation } \\
\hline Tidal volume (ml/kg predicted body weight) & $9.2(2.8)$ & $6.5(2.0)^{*}$ \\
\hline Patients with tidal volume $<8 \mathrm{ml} / \mathrm{kg}(\%)$ & 24 & 92 * \\
\hline Inspiratory plateau pressure $\left(\mathrm{cmH}_{2} \mathrm{O}\right)$ & $16(5)$ & $12(4)^{\star}$ \\
\hline Positive end-expiratory pressure $\left(\mathrm{cmH}_{2} \mathrm{O}\right)$ & $3(2)$ & $3(3)$ \\
\hline Dynamic compliance $\left(\mathrm{ml} / \mathrm{cmH}_{2} \mathrm{O}\right)$ & $52.4(9.1)$ & $53.5(8.7)$ \\
\hline Inspiratory oxygen fraction (\%) & $40(4)$ & $38(13)$ \\
\hline Respiratory rate (cycle/minute) & $11(1)$ & $14(2)^{\star}$ \\
\hline \multicolumn{3}{|l|}{ One-lung ventilation } \\
\hline Tidal volume (ml/kg predicted body weight) & $7.1(1.2)$ & $5.3(1.1)^{*}$ \\
\hline Inspiratory plateau pressure $\left(\mathrm{cmH}_{2} \mathrm{O}\right)$ & $20(7)$ & $15(6)^{*}$ \\
\hline Positive end-expiratory pressure $\left(\mathrm{cmH}_{2} \mathrm{O}\right)$ & $3.3(2.1)$ & $6.2(2.4)^{*}$ \\
\hline Dynamic compliance $\left(\mathrm{ml} / \mathrm{cmH}_{2} \mathrm{O}\right)$ & $32.2(7.5)$ & $44.6(6.9)^{\star}$ \\
\hline Inspiratory oxygen fraction (\%) & $64(9)$ & $67(8)$ \\
\hline Respiratory rate (cycle/minute) & $13(2)$ & $15(2)^{\star}$ \\
\hline
\end{tabular}

Data presented as mean (standard deviation) or percentage. ${ }^{\star} P<0.05$ between the two groups.

$<8 \mathrm{ml} / \mathrm{kg}$ presented a trend for a lower rate of ALI (0.8\% vs. $4.9 \%$ in patients ventilated with $\mathrm{V}_{\mathrm{T}}>8 \mathrm{ml} / \mathrm{kg}, P=0.08$ ).

The cause of death was primarily attributed to ALI in one out of five patients in the PLV group (vs. 6/20 in the historical controls), other causes being related to sepsis (2/5 vs. 4/20, respectively), thromboembolism ( $1 / 5$ vs. $3 / 20$, respectively) and myocardial infarct (1/5 vs. 1 , respectively). Inhospital mortality and the incidence of cardiovascular complications and secondary ALI did not differ between the two groups.

When adjusted for baseline characteristics and perioperative nonrespiratory management, the PLV intervention was associated with a decreased likelihood of ALI occurrence (adjusted odds ratio $=0.34$ with $95 \%$ confidence interval $=0.23$ to $0.75 ; P=0.002$ ). As detailed in Table 5 , multivariate logistic regression analysis identified other independent risk factors for ALI: the extent of lung resection (pneumonectomy, adjusted odds ratio $=2.52$ with $95 \%$ confidence interval $=$ 1.34 to 7.71 ), $\mathrm{V}_{\mathrm{T}}$ (adjusted odds ratio $=1.17 \mathrm{per} \mathrm{ml} / \mathrm{kg}$ increase with $95 \%$ confidence interval $=1.02$ to 1.26 ), alcohol consumption (exceeding $60 \mathrm{~g}$ per day, adjusted odds ratio $=$ 1.93 with $95 \%$ confidence interval $=1.14$ to 5.71 ) and the cumulated amount of perioperative fluid infused (adjusted odds ratio $=1.42$ per $1 \mathrm{ml} / \mathrm{kg} /$ hour increase with $95 \%$ confidence interval $=1.09$ to 4.32 ). There was no evidence that additional covariates would improve the model $(P=0.21$ by the Wald link specification test). The $c$-index for this model was 0.64 and the Hosmer-Lemeshow test for lack of fit was not significant $(P=0.56)$.

\section{Discussion}

The present observational study is the first to indicate that implementation of an intraoperative ventilatory strategy aimed to limit lung overdistension while maintaining functional residual capacity with external PEEP and recruitment maneuvers leads to significant reduction in the incidence of post-thoracotomy ALI and atelectasis along with fewer admissions to the ICU and a shorter hospital stay.

Importantly, lowering the risk of ALI with PLV by more than $50 \%$ was independent of age, severity of underlying lung and cardiovascular diseases as well as other perioperative interventions. Although the present results were obtained by comparison with a historical control group, they strongly suggest that the PLV strategy may also benefit patients undergoing lung cancer resection. Alternatively, the improved respiratory outcome in PLV-treated patients supports the hypothesis that $\mathrm{ALI}$ and atelectasis may in part be caused by or be related to intraoperative factors: ventilator-induced lung injury or ventilator-associated injuries and the reduction of functional residual capacity consequent to the effects of surgical insults, anesthesia and muscle paralysis [14,15]. High shear stress associated with cyclic opening of collapsed areas (atelectotrauma) 


\begin{tabular}{|c|c|c|c|}
\hline & Historical control cohort $(n=533)$ & PLV cohort $(n=558)$ & $P$ value \\
\hline Length of hospital stay (days) & $14.5(3.3)$ & $11.8(4.1)^{\star}$ & $<0.001$ \\
\hline Admission to the intensive care unit (\%) & 9.4 & $2.5^{\star}$ & $<0.001$ \\
\hline Mortality (\%) & 2.8 & 2.3 & 0.753 \\
\hline Reoperation (\%) & 1.0 & 1.6 & 0.687 \\
\hline Respiratory complications (\%) & 14.4 & 10.8 & 0.080 \\
\hline Atelectasis & 8.8 & $5.0^{*}$ & 0.018 \\
\hline Pneumonia & 5.6 & 4.1 & 0.309 \\
\hline Bronchopleural fistula & 1.5 & 1.3 & 0.873 \\
\hline Acute lung injury & 3.8 & $0.9^{*}$ & 0.032 \\
\hline Pneumonectomy & 10.7 & 3.1 & 0.094 \\
\hline Lobectomy, bi-lobectomy & 1.7 & 0.2 & 0.174 \\
\hline Lesser resection & 3.8 & 0.7 & 0.282 \\
\hline Mechanical ventilation $>24$ hours & 4.1 & 3.5 & 0.379 \\
\hline Cardiovascular complications (\%) & 12.0 & 11.3 & 0.723 \\
\hline Myocardial infarct & 1.3 & 0.9 & 0.711 \\
\hline Heart failure & 0.9 & 1.4 & 0.635 \\
\hline Stroke & 0.8 & 0.7 & 0.951 \\
\hline Arrhythmia's & 11.8 & 10.4 & 0.514 \\
\hline Renal dysfunction & 5.1 & 3.0 & 0.123 \\
\hline
\end{tabular}

Data presented as mean (standard deviation) or percentage. ${ }^{*} P<0.05$ between the two groups; $\chi^{2}$ test with Yates correction or unpaired Student $t$ test.

and deformation of the alveolar epithelium (strain) during onelung ventilation are thought to generate a proinflammatory state (biotrauma) leading to pulmonary tissue alterations.

By the late 1990s the standard $V_{T}$ for managing thoracic surgical patients had already been adjusted downwards (from 10 to $12 \mathrm{ml} / \mathrm{kg}$ in the $1980 \mathrm{~s}$ ) to 8 to $10 \mathrm{ml} / \mathrm{kg}$, although no specific guidelines existed for one-lung ventilation. Our historical control data were consistent with these values and, after implementation of the PLV protocol, the $V_{T}$ declined from mean values of 7.1 to $5.3 \mathrm{ml} / \mathrm{kg}$ during the one-lung ventilation period. We used predicted rather than actual body weight for calculating the $V_{T}$ per kilogram of body weight to avoid lung overdistension in obese patients and in women who have smaller lung volumes [16]. Importantly, the ventilatory endpoints $\left(\mathrm{V}_{\mathrm{T}}<8 \mathrm{ml} / \mathrm{kg}\right.$ and inspiratory plateau pressure $<35$ $\mathrm{CmH}_{2} \mathrm{O}$ ) were achieved in more than $80 \%$ of patients. Compliance with the new ventilatory guidelines was facilitated by the relatively short ventilatory time $(<3$ hours), the absence of acute critical illnesses and the commitment of a small number of cardiothoracic anesthesiologists. Interestingly, similar protective ventilatory strategies applied in ICU settings have been associated with a decreased incidence of $A L I$ in high-risk patients, although the target $\mathrm{V}_{\mathrm{T}}$ was achieved in only $50 \%$ to $60 \%$ of cases [17-19].

Thoracic surgical candidates represent a particular group of noncritically ill patients in whom ventilation-induced cytokine upregulation produces a proinflammatory state that renders the host more vulnerable to subsequent hit(s) such as ischemia-reperfusion, hypoxia-reoxygenation and direct tissue trauma [20-22]. Depletion of pulmonary glutathione stores observed in alcoholic patients is expected to further exacerbate oxidative lung injuries [23].

To date, three randomized controlled trials including patients undergoing thoracotomy have compared the application of traditional high $\mathrm{V}_{\mathrm{T}}$ with the open lung strategy combining low $\mathrm{V}_{\mathrm{T}}$ and PEEP. Although Wrigge and colleagues failed to document any difference in systemic inflammatory markers [24], Schilling and colleagues found reduced alveolar concentrations of TNF $\alpha$ and soluble intercellular adhesion molecules in patients ventilated with small $\mathrm{V}_{\mathrm{T}}$ (5 vs. $10 \mathrm{ml} / \mathrm{kg}$ ) [25]. Confirming these positive results, Michelet and colleagues reported an attenuated systemic proinflammatory response, lower interstitial pulmonary edema and an improved oxygenation index 
Table 5

\begin{tabular}{|c|c|c|c|c|}
\hline \multirow[t]{2}{*}{ Characteristic } & \multicolumn{2}{|l|}{ Unadjusted analysis } & \multicolumn{2}{|l|}{ Adjusted analysis } \\
\hline & Odds ratio ( $95 \%$ confidence interval) & $P$ value & Odds ratio ( $95 \%$ confidence interval) & $P$ value \\
\hline Age, per 10-year increase & 1.09 (0.80 to 1.89$)$ & 0.382 & - & - \\
\hline Chronic alcohol consumption & $1.76(1.11$ to 5.2$)$ & 0.013 & $1.93(1.14$ to 5.71$)$ & 0.001 \\
\hline FEV $1<60 \%$ & 1.12 (0.78 to 2.05$)$ & 0.254 & - & - \\
\hline ASA class $3 / 4$ & $1.21(0.72$ to 2.21$)$ & 0.214 & - & - \\
\hline ACE inhibitor therapy & 0.85 (0.55 to 2.12$)$ & 0.315 & - & - \\
\hline Statin therapy & $0.81(0.45$ to 2.97$)$ & 0.198 & - & - \\
\hline Chemo-radiotherapy & 1.52 (1.09 to 3.83$)$ & 0.021 & $1.40(0.91$ to 2.98$)$ & 0.203 \\
\hline Advanced TNM stages (III to IV) & $1.63(1.09$ to 3.01$)$ & 0.018 & 1.45 (0.87 to 2.84$)$ & 0.234 \\
\hline Thoracic epidural anesthesia & 0.92 (0.78 to 1.92$)$ & 0.563 & - & - \\
\hline Duration of surgery & 1.37 (0.78 to 2.67$)$ & 0.312 & - & - \\
\hline Red blood cell transfusion & $1.09(0.23$ to 7.24$)$ & 0.789 & - & - \\
\hline Pneumonectomy & 2.41 (1.29 to 8.12$)$ & 0.005 & 2.52 (1.34 to 7.71$)$ & $<0.001$ \\
\hline Fluid infused, per $1 \mathrm{ml} / \mathrm{kg} / \mathrm{hour}$ increase & $1.33(1.02$ to 5.08$)$ & 0.032 & 1.42 (1.09 to 4.32$)$ & 0.011 \\
\hline
\end{tabular}

ACE, angiotensin-converting enzyme; ASA, American Society of Anesthesiologists; FEV ${ }_{1}$, forced expiratory volume in 1 second; TNM, Tumor, Node, Metastasis.

allowing earlier extubation in the protective ventilation group among patients undergoing esophagectomy [26].

In the present study we adopted a PLV including pressurecontrolled ventilation, external PEEP and recruitment maneuvers. Actually, delivery of a decelerating gas flow has been reported to achieve more homogeneous flow distribution and lower peak airway pressure [27]. Different lung recruitment strategies have been shown to re-expand the collapsed dependent lung areas that develop in almost all anesthetized patients. During thoracic surgery, application of recruitment maneuvers with moderate PEEP levels to the dependent lung has been shown to improve oxygenation and to reduce both intrinsic PEEP levels and static elastance of the respiratory system without causing significant cardiovascular deterioration [28]. Our data confirm the good hemodynamic tolerance to the PLV protocol since fluid and vasopressor requirements were similar in the two cohorts. Given the difficulties in constructing static pressure-volume curves, we did not titrate the PEEP but we set a fixed moderate level of PEEP that could potentially cause alveolar hyperinflation in healthy or emphysematous areas. This possibility seems unlikely since we observed higher compliance in patients managed with the PLV protocol, which supports the stabilizing effects of PEEP along with effective re-expansion of previously collapsed areas following recruitment maneuvers [29-31].

We acknowledge several limitations in the current study. Although data were collected by clinicians and validated by scientific investigators, we assume variability in initial ventilator settings with the possibility that higher inspiratory pressures and tidal volume were deliberately chosen to correct transient hypoxemia and hypercapnia. The observational design limits the ability to infer causality between the lung-protective protocol and lowering the incidence of ALI. Although statistics were helpful to adjust for some confounding variables, unmeasured factors and other changes in practice or in the patient case mix may have decreased the confidence in observed effects. For instance, potentially beneficial therapies such as preoperative statin and angiotensin-converting enzyme treatment, continuous thoracic epidural anesthesia, goal-directed fluid therapy using transesophageal Doppler monitoring, inhalation of $\beta_{2}$ agonists in high-risk patients, and early postoperative mobilization were popularized during the postintervention period, and thereby could have contributed to the overall reduction in respiratory complications and in hospital length of stay [32]. On the other hand, despite higher prevalence of hypertension in the protocol-treated cohort, mortality and cardiovascular adverse events were unchanged compared with the control cohort. Finally, major limitations also stem from the definition of ALI that may cover different clinical patterns and histological findings, which may explain significant interobserver diagnostic disagreement particularly in postoperative patients [33]. In the present study, we excluded patients with delayed onset of ALI triggered by infection, bronchial aspiration of gastric content and allogenic transfusion. Accordingly, post-thoracotomy ALI probably identified a more homogeneous group of patients predisposed to the injurious effects of mechanical ventilation. 
The reliability of $\mathrm{ALI}$ diagnostic criteria could have been improved by additional measurements of plasma brain natriuretic factor and lung water content with the transpulmonary thermodilution technique $[34,35]$.

\section{Conclusions}

In this observational study, we demonstrated the effectiveness of combining low $V_{T}$, PEEP and recruitment maneuvers. This intraoperative open-lung approach was easily implemented in clinical practice and resulted in a reduced incidence of postoperative ALI and atelectasis. Implementation of a bundle of scientifically-based perioperative interventions represents an integral component of clinical quality management. Future clinical trials will determine whether optimization of other ventilator settings (for example, oxygen inspiratory fraction, PEEP level, periodicity of recruitment maneuver) may improve respiratory outcome in specific groups of surgical patients requiring mechanical ventilation.

\section{Key messages}

- Intraoperative application of a small tidal volume, PEEP and recruitment maneuvers was successfully achieved in $92 \%$ patients undergoing lung cancer resection over a 5 -year period.

- Adoption of the presented lung ventilatory strategy was associated with a reduced incidence of acute lung injury ( $0.9 \%$ vs. $3.7 \%)$ and atelectasis ( $5 \%$ vs. $8.8 \%)$, and with fewer admissions to the ICU (2.5\% vs. $9.4 \%)$ and a shorter length of hospital stay (11.8 $\pm 4.1 \mathrm{vs.}$ $14.5 \pm 3.3$ days).

- Traditional intraoperative ventilatory settings can be harmful, and therefore new guidelines should be proposed.

\section{Competing interests}

The authors declare that they have no competing interests.

\section{Authors' contributions}

$\mathrm{ML}$ and J-MT participated in the study design, data analysis and interpretation of the data as well as the writing of the manuscript. JD, VL and $\mathrm{ML}$ participated in the data collection and statistical analysis. JD, YV and JR participated in the literature search and interpretation of the study. AS and JR participated in revising the bibliography, and correcting and editing the manuscript. All authors read and approved the final manuscript.

\section{Additional files}

The following Additional files are available online:

\section{Additional file 1}

A word file containing a table that lists the major nonfatal complications occurring during the inhospital postoperative stay. Standard criteria are used to define these adverse events.

See http://www.biomedcentral.com/content/ supplementary/cc7762-S1.doc

\section{Acknowledgements}

The Lancardis Fundation in Sion (Switzerland) granted support for this study. No source influenced the study design, data collection, analysis, reporting, or decision to submit the manuscript for publication.

\section{References}

1. Boffa DJ, Allen MS, Grab JD, Gaissert HA, Harpole DH, Wright CD: Data from The Society of Thoracic Surgeons General Thoracic Surgery database: the surgical management of primary lung tumors. J Thorac Cardiovasc Surg 2008, 135:247-254

2. Memtsoudis SG, Besculides MC, Zellos L, Patil N, Rogers SO: Trends in lung surgery: United States 1988 to 2002. Chest 2006, 130:1462-1470.

3. Goodney PP, Lucas FL, Stukel TA, Birkmeyer JD: Surgeon specialty and operative mortality with lung resection. Ann Surg 2005, 241:179-184.

4. Alam N, Park BJ, Wilton A, Seshan VE, Bains MS, Downey RJ, Flores RM, Rizk N, Rusch VW, Amar D: Incidence and risk factors for lung injury after lung cancer resection. Ann Thorac Surg 2007, 84:1085-1091.

5. Licker MJ, Widikker I, Robert J, Frey JG, Spiliopoulos A, Ellenberger C, Schweizer A, Tschopp JM: Operative mortality and respiratory complications after lung resection for cancer: impact of chronic obstructive pulmonary disease and time trends. Ann Thorac Surg 2006, 81:1830-1837.

6. Bernard GR, Artigas A, Brigham KL, Carlet J, Falke K, Hudson L, Lamy M, LeGall JR, Morris A, Spragg R: Report of the AmericanEuropean consensus conference on ARDS: definitions, mechanisms, relevant outcomes and clinical trial coordination. The Consensus Committee. Intensive Care Med 1994, 20:225-232.

7. Licker $M$, Fauconnet $P$, Villiger $Y$, Tschopp JM: Acute lung injury and outcomes after thoracic surgery. Curr Opin Anaesthesiol 2009, 22:61-67.

8. Tang SS, Redmond K, Griffiths M, Ladas G, Goldstraw P, Dusmet $M$ : The mortality from acute respiratory distress syndrome after pulmonary resection is reducing: a 10-year single institutional experience. Eur J Cardiothorac Surg 2008, 34:898-902.

9. Fernandez-Perez ER, Keegan MT, Brown DR, Hubmayr RD, Gajic $\mathrm{O}$ : Intraoperative tidal volume as a risk factor for respiratory failure after pneumonectomy. Anesthesiology 2006, 105:14-18.

10. Licker M, de Perrot M, Spiliopoulos A, Robert J, Diaper J, Chevalley C, Tschopp JM: Risk factors for acute lung injury after thoracic surgery for lung cancer. Anesth Analg 2003, 97:1558-1565.

11. Schultz MJ: Lung-protective mechanical ventilation with lower tidal volumes in patients not suffering from acute lung injury: a review of clinical studies. Med Sci Monit 2008, 14:RA22-RA26.

12. Petrucci $N$, lacovelli $W$ : Lung protective ventilation strategy for the acute respiratory distress syndrome. Cochrane Database Syst Rev 2007:CD003844.

13. Vittinghoff EGD, Shibosky SC, McCulloch CE: Regression methods in biostatistics: linear, logistic, survival, and repeated measures of models. Springer New York; 2005:72-93. 
14. Hedenstierna G, Edmark L: The effects of anesthesia and muscle paralysis on the respiratory system. Intensive Care Med 2005, 31:1327-1335.

15. Kozian A, Schilling T, Freden F, Maripuu E, Rocken C, Strang C, Hachenberg T, Hedenstierna G: One-lung ventilation induces hyperperfusion and alveolar damage in the ventilated lung: an experimental study. Br J Anaesth 2008, 100:549-559.

16. Steinberg KP, Kacmarek RM: Respiratory controversies in the critical care setting. Should tidal volume be $6 \mathrm{~mL} / \mathrm{kg}$ predicted body weight in virtually all patients with acute respiratory failure? Respir Care 2007, 52:556-564.

17. Yilmaz M, Keegan MT, Iscimen R, Afessa B, Buck CF, Hubmayr $\mathrm{RD}$, Gajic $\mathrm{O}$ : Toward the prevention of acute lung injury: protocol-guided limitation of large tidal volume ventilation and inappropriate transfusion. Crit Care Med 2007, 35:1660-1666.

18. Davis JL, Morris A, Kallet RH, Powell K, Chi AS, Bensley M, Luce $J M$, Huang L: Low tidal volume ventilation is associated with reduced mortality in HIV-infected patients with acute lung injury. Thorax 2008, 63:988-993.

19. Umoh NJ, Fan E, Mendez-Tellez PA, Sevransky JE, Dennison CR, Shanholtz C, Pronovost PJ, Needham DM: Patient and intensive care unit organizational factors associated with low tidal volume ventilation in acute lung injury. Crit Care Med 2008, 36:1463-1468.

20. Kuzkov VV, Suborov EV, Kirov MY, Kuklin VN, Sobhkhez M, Johnsen S, Waerhaug K, Bjertnaes LJ: Extravascular lung water after pneumonectomy and one-lung ventilation in sheep. Crit Care Med 2007, 35:1550-1559.

21. Cheng YJ, Chan KC, Chien CT, Sun WZ, Lin CJ: Oxidative stress during 1-lung ventilation. J Thorac Cardiovasc Surg 2006, 132:513-518.

22. Meier $\mathrm{T}$, Lange $\mathrm{A}$, Papenberg $\mathrm{H}$, Ziemann $\mathrm{M}$, Fentrop $\mathrm{C}$, Uhlig $\mathrm{U}$, Schmucker P, Uhlig S, Stamme C: Pulmonary cytokine responses during mechanical ventilation of noninjured lungs with and without end-expiratory pressure. Anesth Analg 2008, 107:1265-1275.

23. Joshi PC, Guidot DM: The alcoholic lung: epidemiology, pathophysiology, and potential therapies. Am J Physiol Lung Cell Mol Physiol 2007, 292:L813-L823.

24. Wrigge $H$, Uhlig $U$, Zinserling J, Behrends-Callsen $E$, Ottersbach G, Fischer M, Uhlig S, Putensen C: The effects of different ventilatory settings on pulmonary and systemic inflammatory responses during major surgery. Anesth Analg 2004, 98:775-781.

25. Schilling T, Kozian A, Huth C, Buhling F, Kretzschmar M, Welte T, Hachenberg $\mathrm{T}$ : The pulmonary immune effects of mechanical ventilation in patients undergoing thoracic surgery. Anesth Analg 2005, 101:957-965.

26. Michelet $P, D^{\prime}$ Journo XB, Roch A, Doddoli C, Marin V, Papazian L, Decamps I, Bregeon F, Thomas P, Auffray JP: Protective ventilation influences systemic inflammation after esophagectomy: a randomized controlled study. Anesthesiology 2006, 105:911-919

27. Unzueta MC Casas ال Moral MV: Pressure-controlled versus volume-controlled ventilation during one-lung ventilation for thoracic surgery. Anesth Analg 2007, 104:1029-1033.

28. Cinnella G, Grasso S, Natale C, Sollitto F, Cacciapaglia M, Angiolillo M, Pavone G, Mirabella L, Dambrosio M: Physiological effects of a lung-recruiting strategy applied during one-lung ventilation. Acta Anaesthesiol Scand 2008, 52:766-775.

29. Farias LL, Faffe DS, Xisto DGMC, Lassance R, Prota LF, Amato $\mathrm{MB}$, Morales MM, Zin WA, Rocco PR: Positive end-expiratory pressure prevents lung mechanical stress caused by recruitment/derecruitment. J Appl Physiol 2005, 98:53-61.

30. Slinger PD, Kruger M, McRae K, Winton T: Relation of the static compliance curve and positive end-expiratory pressure to oxygenation during one-lung ventilation. Anesthesiology 2001, 95:1096-1102.

31. Pavone L, Albert S, DiRocco J, Gatto L, Nieman G: Alveolar instability caused by mechanical ventilation initially damages the nondependent normal lung. Crit Care 2007, 11:R104.

32. Licker M, Tschopp JM, Robert J, Frey JG, Diaper J, Ellenberger C: Aerosolized salbutamol accelerates the resolution of pulmonary edema after lung resection for cancer. Chest 2008, 133:845-852.
33. Phua J, Stewart TE, Ferguson ND: Acute respiratory distress syndrome $\mathbf{4 0}$ years later: time to revisit its definition. Crit Care Med 2008, 36:2912-2921.

34. Monnet X, Anguel N, Osman D, Hamzaoui O, Richard C, Teboul JL: Assessing pulmonary permeability by transpulmonary thermodilution allows differentiation of hydrostatic pulmonary edema from ALI/ARDS. Intensive Care Med 2007, 33:448-453.

35. Karmpaliotis D, Kirtane AJ, Ruisi CP, Polonsky T, Malhotra A, Talmor D, Kosmidou I, Jarolim P, de Lemos JA, Sabatine MS, Gibson $\mathrm{CM}$, Morrow D: Diagnostic and prognostic utility of brain natriuretic peptide in subjects admitted to the ICU with hypoxic respiratory failure due to noncardiogenic and cardiogenic pulmonary edema. Chest 2007, 131:964-971. 